\title{
Identification of a Chicken Anemia Virus Variant-Related Gyrovirus in Stray Cats in China, 2012
}

\author{
Xinheng Zhang, ${ }^{1}$ Yuanjia Liu, ${ }^{2}$ Jun Ji, ${ }^{1}$ Feng Chen,, Baoli Sun, \\ Chunyi Xue, ${ }^{3}$ Jingyun $\mathrm{Ma}^{1}{ }^{1}$ Yingzuo $\mathrm{Bi}^{1}{ }^{1}$ and Qingmei $\mathrm{Xie}^{1,4}$ \\ ${ }^{1}$ College of Animal Science, South China Agricultural University, Wushan Road, Tianhe District, Guangzhou, \\ Guangdong 510642, China \\ ${ }^{2}$ College of Veterinary Medicine, South China Agricultural University, Guangzhou 510642, China \\ ${ }^{3}$ State Key Laboratory of Biocontrol, College of Life Sciences, Sun Yat-Sen University, Guangzhou 510006, China \\ ${ }^{4}$ Key Laboratory of Chicken Genetics, Breeding and Reproduction, Ministry of Agriculture, Guangzhou 510642, China
}

Correspondence should be addressed to Qingmei Xie; qmx@scau.edu.cn

Received 14 October 2013; Revised 25 December 2013; Accepted 27 December 2013; Published 13 February 2014

Academic Editor: Marcelo A. Soares

Copyright (C) 2014 Xinheng Zhang et al. This is an open access article distributed under the Creative Commons Attribution License, which permits unrestricted use, distribution, and reproduction in any medium, provided the original work is properly cited.

\begin{abstract}
The chicken anemia virus (CAV), is a known member of the genus Gyrovirus and was first isolated from chickens in Japan in 1979. Some reports have also demonstrated that CAV can be identified in human stool specimens. In this study, a variant of CAV was detected using PCR with CAV-based primers in fecal samples of stray cats. The genome of CAV variant was sequenced and the results suggest that it could be a recombinant viral strain from parental CAV strains JQ690762 and AF311900. Recombination is an important evolutionary mechanism that contributes to genetic diversification. These findings indicate that CAV variant might have originated from CAV-infected chickens. The epidemiology and pathogenesis of this novel virus remains to be elucidated. This study underscores the importance of CAV surveillance and it presents the first evidence suggesting the possibility of CAV homologous recombination in cat.
\end{abstract}

\section{Introduction}

The chicken anemia virus (CAV) is a transmissible pathogen that infects young chickens, resulting in aplastic anemia, hemorrhages in the muscle and subcutaneous tissues, thymus atrophy, and severe immune suppression [1]. The infection can be propagated within the flock both vertically and horizontally. CAV is a member of the Gyrovirus genus, belonging to the family Circoviridae [2]. The CAV genome is comprised of single-stranded, circular DNA approximately $2.3 \mathrm{~kb}$ in length, with three partially overlapping open reading frames (ORFs), coding for the VP1, VP2, and VP3 proteins [3]. VP3, also named apoptin, is a proapoptotic protein. Infection with this virus, which is mainly transmitted through contaminated feathers, has been shown to trigger apoptosis in thymocytes and myeloid progenitor cells in young chickens [4]. Viral surveillance programs have isolated more than 50
CAV samples from different provinces in China during 20092012, and the epidemiological analysis suggested that CAVs were prevalent in China. We also analyzed the characteristic of one strain (GD-1-12), which was isolated in Southern China in 2012; the GD-1-12 isolate's genome at position 183 has a $21 \mathrm{nt}$ deletion (TCCGTACAGGGGGGTACGTCA) in comparison with the genome (accession no. JQ690762) of the CAV isolate from human fecal samples. It is unclear if the $21 \mathrm{nt}$ deletion is related to host specificity or pathogenicity [5]. In 2010, the CAV genome has been detected in breeder and commercial chicken flocks in South Korea [6]. The CAV (JQ690762) was also detected in pediatric fecal samples in Beijing, China (http://www.ncbi.nlm.nih.gov/nuccore/JQ690762/) [7]. In 2011, a novel human virus was identified on the surface of human skin and was designated human gyrovirus (HGyV), due to its homology with the chicken anemia virus [8]. In 2012, another gyrovirus species named GyV3 
was detected in diarrhoea and normal faeces from Chilean children in the USA, which may reflect consumption of CAV-infected/vaccinated chickens due to the low sequence similarity with other gyroviruses [9]. Another gyrovirus (GyV4) was identified in human stool samples and in chicken meat sold for human consumption in Hong Kong in 2012 [10]. In the same year, four HGyV DNA samples were detected, three were from kidney transplant recipients and one was from an HIV-infected patient in Italy [11]. Human gyrovirus apoptin protein (VP3) has a similar subcellular distribution pattern and apoptotic function as its CAV homolog [12]. However, whether or not the first gyrovirus-carrying human was infected by eating CAV-infected/vaccinated chickens and the molecular mechanism of $\mathrm{HGyV}$ infection are still unclear and require further study. Cases of CAV recombination have been reported in chickens in China and the only recombination region is located in the coding region of VP1 $[13,14]$. In this study, the first evidence of CAV homologous recombination in cats is explored in an attempt to elucidate the mechanism through which CAV infects various species.

\section{Materials and Methods}

2.1. Clinical Specimens. In order to identify circulating CAV viruses in cats in Southern China, 102 fecal samples were selected from two humane shelters located in Baiyun district $(n=40)$ and Conghua $(n=62)$ district of Guangzhou in 2012, where stray cats were most widespread in the south central area of Guangdong Province.

2.2. Extraction of Viral DNA. Viral DNA was extracted from 102 fecal samples using a commercial DNA extraction kit (QIAamp DNA Stool Mini Kit, QIAgen, Hilden, Germany) according to the manufacturer's instructions. The DNA was then quantitated and stored at $-20^{\circ} \mathrm{C}$ until PCR was performed.

2.3. Virus Detection by PCR. The extracted DNA was screened by PCR. The primers were as sollows: JCP1: $5^{\prime} \mathrm{CATC}$ AACGGTGTTCAGGC3' and JCP2: $5^{\prime}$ CCTTGGAAGCGGA TAGTCAT3'. Primers were designed by Primer Premier 5.0 to amplify $535 \mathrm{bp}$ from the partial coding regions of CAV. The PCR amplification was performed in a total volume of $25 \mathrm{uL}$, including $12.5 \mathrm{uL}$ of buffer I, $4 \mathrm{uL}$ dNTPs, $0.5 \mathrm{uL}$ of each primer, $6 \mathrm{uL}$ distilled water, $1 \mathrm{uL}$ DNA, and $0.5 \mathrm{uL}$ LA Taq polymerase (TaKaRa, Biotechnology, Dalian, China). Amplification reactions were performed using the automated thermal cycler (Gene Amp PCR System 9700, Applied Biosystems, Foster City, CA, USA) with the following cycling profile: initial denaturation at $94^{\circ} \mathrm{C}$ for $4 \mathrm{~min}$ followed by 30 cycles of denaturation, annealing, and extension at $94^{\circ} \mathrm{C}$ for $30 \mathrm{~s}, 57^{\circ} \mathrm{C}$ for $30 \mathrm{~s}$, and $72^{\circ} \mathrm{C}$ for $2 \mathrm{~min}$, respectively, and a final extension step was carried out at $72^{\circ} \mathrm{C}$ for $10 \mathrm{~min}$. The $535 \mathrm{bp}$ reaction product was analyzed on $1 \%$ agarose gels. Negative controls were included in every three PCR reactions and one positive control was included in each set of reactions performed. The standardized PCR amplification yielded a distinct band of $535 \mathrm{bp}$ in size as expected.

2.4. Amplification, Cloning, and Sequencing of the CAV Variant Genome. The DNA from the PCR-positive sample of CAV variant was further analyzed by two primers pairs to amplify the complete CAV variant genome. Primers KQ1F, 5' $5^{\prime}$-CAATCACTCTATCGCTGTGT-3' and KQ1R: $5^{\prime}$-TTCGTCCATCTTGACTTTCT-3' and primers KQ2F: $5^{\prime}$-GGCTACTATTCCATC(A/T)CCATTCT-3', and KQ2R: $5^{\prime}$-GCTCGTCTTGCCATCTTACA-3', were designed to amplify $1778 \mathrm{bp}$ and $831 \mathrm{bp}$ fragments, respectively, covering the entire genome. The PCR amplification was carried out in $50 \mathrm{uL}$ volume containing $25 \mathrm{uL}$ buffer I, $16 \mathrm{uL}$ dNTP, $0.5 \mathrm{uL}$ of each primer, $13.5 \mathrm{uL}$ distilled water, $1 \mathrm{uL}$ of the DNA, and $0.5 \mathrm{uL}$ LA Taq polymerase (TaKaRa, Biotechnology, Dalian, China). Amplification of the $831 \mathrm{bp}$ region was carried out using the following PCR conditions: initial denaturation of $94^{\circ} \mathrm{C}$ for $4 \mathrm{~min}$ followed by 30 cycles of denaturation, annealing, and extension at $94^{\circ} \mathrm{C}$ for $30 \mathrm{~s}, 59^{\circ} \mathrm{C}$ for $30 \mathrm{~s}$, and $72^{\circ} \mathrm{C}$ for $2 \mathrm{~min}$, respectively, and a final extension step was carried out at $72^{\circ} \mathrm{C}$ for $10 \mathrm{~min}$. Amplification of the $1778 \mathrm{bp}$ region proceeded for 35 cycles as follows: $5 \mathrm{~min}$ at $94^{\circ} \mathrm{C}, 30 \mathrm{~s}$ at $94^{\circ} \mathrm{C}, 30 \mathrm{~s}$ at $58^{\circ} \mathrm{C}, 2 \mathrm{~min} 30 \mathrm{~s}$ at $72^{\circ} \mathrm{C}$, and a final extension step was carried out at $72^{\circ} \mathrm{C}$ for $10 \mathrm{~min}$. PCR amplification products were analyzed on $1 \%$ agarose gels stained with ethidium bromide. PCR products were purified using the Gel Band Purification Kit (Omega Bio-Tek, USA) and cloned into the pMD19-T vector (TaKaRa Bio Inc, Japan) followed by sequencing in triplicate using an ABI 3730 Sanger-based genetic analyzer (Carlsbad, CA, USA).

2.5. Sequence Alignment. The complete nucleotide sequence of CAV variant and reference sequences from different hosts from various countries were available from GenBank (Table 1). The DNA sequences and amino acid sequences were assembled using DNAStar (version 7; Madison, WI, USA) and Multiple sequence alignment was performed with the Clustal X (BioEdit version 7) program. Phylogenetic trees were constructed for genome sequences using the MEGA 5.1 program [15].

2.6. Sequence Recombination Analysis. Detection of potential recombinant sequences, identification of potential parental sequences, and localization of possible recombination break points were performed with the Recombination Detection Program (RDP4) v.4.1.3 [16]. Five different methods (RDP, Chimaera, MaxChi, Bootscan, and 3Seq) were used to detect recombination events in Cat-GyV. Meanwhile, in order to confirm the results, putative recombinant sequences and their parental strains were further analyzed with Simplot version 3.5.1 [17]. Evidence for networked relationships in CAV variant was examined using MEGA 5.1. 
TABLE 1: The GenBank accession numbers of full-length CAV genomes in isolates from different host species.

\begin{tabular}{|c|c|c|c|c|}
\hline Accession number & Strain name & Host & Year & Country (area) \\
\hline AB046589 & AH9410 & Chicken & 2001 & Japan \\
\hline AF285882 & SMSC-1 & Chicken & 2003 & Malaysia \\
\hline AF311892 & 98D02152 & Chicken & 2010 & USA \\
\hline AF311900 & 98D06073 & Chicken & 2010 & USA \\
\hline AF390038 & $3-1$ & Chicken & 2003 & Malaysia \\
\hline AF390102 & SMSC-1P60 & Chicken & 2003 & Malaysia \\
\hline AF395114 & $\mathrm{BD}-3$ & Chicken & 2004 & Bangladesh \\
\hline AF475908 & - & Chicken & 2002 & China (Harbin) \\
\hline AJ297684 & Cux-1 & Chicken & 2000 & Germany (Cuxhaven) \\
\hline AY040632 & $3-1 \mathrm{P} 60$ & Chicken & 2003 & Malaysia \\
\hline AJ297685 & Cux-1 & Chicken & 2000 & Germany (Cuxhaven) \\
\hline AY839944 & LF4 & Chicken & 2004 & China \\
\hline AY843527 & TJBD33 & Silkies & 2005 & China \\
\hline AY846844 & TJBD40 & Chicken & 2004 & China \\
\hline AY999018 & $\mathrm{SD} 24$ & Chicken & 2005 & China \\
\hline CAU65414 & 704 & Chicken & 1996 & Australia \\
\hline CAU66304 & isolate 10 & Chicken & 1997 & UK \\
\hline DQ124935 & AH6 & Chicken & 2005 & China (Anhui) \\
\hline DQ124936 & $\mathrm{AH} 4$ & Chicken & 2005 & China (Anhui) \\
\hline DQ141670 & SH11 & Chicken & 2005 & China (Shanghai) \\
\hline DQ141671 & SH16 & Chicken & 2005 & China (Shanghai) \\
\hline DQ141672 & HN9 & Chicken & 2005 & China (Henan) \\
\hline DQ141673 & SD22 & Chicken & 2005 & China (Shandong) \\
\hline DQ217400 & SMSC-1P9WT & Chicken & 2005 & Malaysia \\
\hline DQ217401 & SMSC-1P123WT & Chicken & 2005 & Malaysia \\
\hline DQ991394 & $01-4201$ & Chicken & 2007 & USA \\
\hline EF176599 & $\mathrm{C} 14$ & Chicken & 2007 & China \\
\hline FJ172347 & SDLY08 & Broiler chicken & 2008 & China \\
\hline HM590588 & AGV2 & Chicken & 2011 & Brazil \\
\hline JF507715 & CIAV89-69 & Chicken & 1991 & South Korea \\
\hline JQ308210 & GyV3 & Human & 2011 & USA \\
\hline JQ690762 & AGV2 & Human & 2012 & China \\
\hline JX260426 & GD-1-12 & Chicken & 2012 & China (Guangdong) \\
\hline M55918 & Cuxhaven-1 & Chicken & 2008 & Netherlands \\
\hline NC_001427 & - & Chicken & 2009 & USA \\
\hline JX310702 & GyV4 & Human and chicken & 2012 & Hong Kong \\
\hline KC414026 & CAV variant & Cat & 2012 & China (in this paper) \\
\hline
\end{tabular}

\section{Results}

3.1. Prevalence of CAV Variant. The survey data showed that the percentage of CAV positive samples was nearly $10 \%$ (10 of 102 fecal samples).

3.2. Molecular Characteristics and Phylogenetic Analysis of $C A V$ Variant. The complete genome sequence of CAV variant was submitted to GenBank, under the accession number KC414026. The CAV variant genome was 2,295 nt long, very close to the genome size $(2,316 \mathrm{nt})$ of the CAV isolated from human fecal samples (accession no. JQ690762). Comparative analyses showed that CAV variant shared the greatest sequence identity (98.1\%) with the CAV isolate from Japan (AH9410) and the least identity (38\%) with the GyV3 isolate from the USA. The VP1, VP2, and VP3 genes of the CAV variant showed nucleotide variations of $1-63.1 \%, 0.5-51.9 \%$, and $0.5-50.5 \%$, respectively, among the 36 relevant sequences from GenBank. Previous studies have confirmed that the VP1 protein has the highest variability with a hypervariable region located from residues 139 to 151, while the amino acids 139 and 144 play vital roles in virus growth and spread, as VP1 residues Q139 and/or Q144 are associated with a decreased rate of spread of CIA-1 isolate [18]. In the CAV variant, VP1 residues 139 and 144 are lysine and glutamic acid, respectively, while in the two CAV isolates JQ690762 and AF311900, they are both 


\begin{tabular}{|c|c|c|c|c|c|c|c|}
\hline & 113 & 341 & 357 & 371 & 20 & 116 & 79 \\
\hline AV & E FP LA & HHRAR & TLAPL & MGVPA & S RGGQ & QSAQA & RTNQP \\
\hline $\mathrm{AH}$ & . L . & $\cdot \mathrm{K} \cdot$ & . V. . & . S A. . & . E. . & $\mathrm{R} \cdot \mathrm{T}$. & . . D. \\
\hline A. & . L . & . . K. . & . . V. . & . A. . & . E . & $\mathrm{R} \cdot \mathrm{T}$. & . D. \\
\hline $\mathrm{AF}$ & $\cdot \mathrm{L} \cdot$ & $\cdot \mathrm{K} \cdot$ & . . V. . & $\cdot$ A. & . E. & $\mathrm{R} \cdot \mathrm{T}$. & . D. \\
\hline 00 & $\cdot \mathrm{L} \cdot$ & . . K. . & . . V. . & . S A. . & . E. & & . D. . \\
\hline & . L . & $\cdot$. K . & . . V. . & . SA. & . E . & $\mathrm{R} \cdot \mathrm{T}$. & . . D. \\
\hline & . L . & $\cdot \mathrm{K} \cdot$ & $\cdot . \mathrm{V}$. & . A. & . E . & $\mathrm{R} \cdot \mathrm{T} \cdot$ & . D. . \\
\hline $\mathrm{AF}$ & $\cdot \mathrm{L} \cdot$ & $\cdot$. K. . &. $\mathrm{V}$. & . TA. & . E. & $\mathrm{R} \cdot \mathrm{T}$. & . D. . \\
\hline & $\cdot \mathrm{L} \cdot$ & $\cdot$. K. . &. $\mathrm{V}$. & - S A. & . E. & $\mathrm{R} \cdot \mathrm{T}$. & . . D. . \\
\hline & $\cdot \mathrm{L} \cdot$ & $\cdot \mathrm{K} \cdot$ & $\cdot \mathrm{V}$. & . S A. & . E . & $\mathrm{R} \cdot \mathrm{T}$. & . . D. \\
\hline 35 & . L . . & . . K. . & . . V.. & . S A. . & . E. . & $\mathrm{R} \cdot \mathrm{T}$. & . D. \\
\hline & $\cdot \mathrm{L} \cdot$ & $\cdot \mathrm{K} \cdot$ &. $\mathrm{V}$. & . A. . & E. . & $\mathrm{R} \cdot \mathrm{T}$. & . D. E \\
\hline & . L. & . . K. . & . . V. . & - SA. & . E. . & $\mathrm{R} \cdot \mathrm{T}$. & . . D. . \\
\hline & $\cdot \mathrm{L} \cdot$ & . . K. . & . . V. & $\cdot \mathrm{A} \cdot$ & . E . & $\mathrm{R} \cdot \mathrm{T}$. & . D. . \\
\hline & $\cdot \mathrm{L} \cdot$ & $\cdot$. K. . & . . V.. & $\cdot \mathrm{A} \cdot$ & . E . & $\mathrm{R} \cdot \mathrm{T}$. & . D. . \\
\hline & . L . & $\cdot \mathrm{K} \cdot \cdot$ &. $\mathrm{V}$. & S A. . & . E. . & $\mathrm{R} \cdot \mathrm{T}$. & . . D. . \\
\hline C & $\cdot \mathrm{L} \cdot$ & . . K. . & 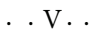 & - S A. . & . E . & $\mathrm{R} \cdot \mathrm{S} \cdot$ & . . D. A \\
\hline & $\cdot \mathrm{L} \cdot$ & $\cdot \mathrm{K} \cdot$ & $\cdot \cdot \mathrm{V}$. & - S A. . & . E. . & $\mathrm{R} \cdot \mathrm{T}$ & . D. \\
\hline & $\cdot \mathrm{L} \cdot \cdot$ & . . K. . & . . V.. & $\mathrm{S} A$. & . E. . & $\mathrm{R} \cdot \mathrm{T}$. & . D. . \\
\hline & $\cdot \mathrm{L} \cdot \cdot$ & $\cdot \mathrm{K} \cdot$ & . . V. . & S A. . & . E. . & $\mathrm{R} \cdot \mathrm{T}$. & . . D. \\
\hline & . L. & $\cdot$. K. . & . . V.. & $\cdot A \cdot$ & . E. . & $\mathrm{R} \cdot \mathrm{T}$ & . D. . \\
\hline & . L & $\cdot \mathrm{K}$. & . . V. . & $\cdot$ A. . & . . E. . & $\mathrm{R} \cdot \mathrm{T}$. & . . D. . \\
\hline 72 & . L . . & $\cdot \mathrm{K} \cdot$. & . . V. . & . A. . & . E . . & $\mathrm{R} \cdot \mathrm{T} \cdot$ & . . D. . \\
\hline & . L . & . K . . & . . V. . & S A. & . E. . & $\mathrm{R} \cdot \mathrm{T}$. & . . D. . \\
\hline & $\cdot \mathrm{L} \cdot$ & . . K. . & . . V. . & S A. & . E. . & $\mathrm{R} \cdot \mathrm{T}$. & . D. . \\
\hline & $\cdot \mathrm{L} \cdot$ & . . K. . & . . V.. & . A. & . E. . & $\mathrm{R} \cdot \mathrm{T}$. & . . D. . \\
\hline & . $\mathrm{L}$ & $\cdot \mathrm{K} \cdot$ & . . V. . & . A. & . E . & $\mathrm{R} \cdot \mathrm{T}$. & . D. . \\
\hline & $\cdot \mathrm{L}$ & . . K. & . . V. & $S A$ & . E. & $\mathrm{R} \cdot \mathrm{T}$. & . D. . \\
\hline & . $\mathrm{L}$ & $\cdot \mathrm{K} \cdot \cdot$ & . . V. & $\cdot \mathrm{A}$ & . . E. . & $\mathrm{R} \cdot \mathrm{T} \cdot$ & . D. . \\
\hline 38 & . M. . & $\mathrm{K} \cdot \mathrm{S}$ I T & . . V. K & . FO. & RQE . . & . ET. T & . . D. . \\
\hline & . . L . & $\cdot \mathrm{K} \cdot$ &. $\mathrm{V}$. & . A & . E. . & $\mathrm{R} \cdot \mathrm{T}$. & . D. . \\
\hline JQ & . . FW. & $\mathrm{K} \cdot \mathrm{VI}$ & . . V.K & . $\mathrm{TK}$ & RQE . . & $\cdot \mathrm{ET} \cdot \mathrm{T}$ & . . . . \\
\hline & $\cdot \mathrm{L}$ & . $\mathrm{K}$. & . . V. & S & . E. & $\mathrm{R} \cdot \mathrm{T}$. & $\cdot \mathrm{D}$. \\
\hline $\mathrm{JX}$ & . L. & . . K. & . V. & . A & E. & $\mathrm{R} \cdot \mathrm{T}$. & . D. . \\
\hline 8 & . . L . & . . K. & . . V. . & $\cdot \mathrm{S} A$ & . E . & $\mathrm{R} \cdot \mathrm{T}$. & $\cdot \mathrm{D}$. \\
\hline 96 & . .M. & $\mathrm{K} \cdot \mathrm{S}$ I T & . . V.K & & RQE . . & $\cdot \mathrm{ET} \cdot \mathrm{T}$ & . . . . \\
\hline NC-001427 & . L & . . K. &. $\mathrm{V}$. & . $\mathrm{S}$ & . E . & $\mathrm{R} \cdot \mathrm{T} \cdot$ & . . D. \\
\hline
\end{tabular}

FIGURE 1: Multisequence alignment of deduced amino acids of the coding region at positions 113, 341, 357, 371 (VP1), 20,116 (VP2), and 79 (VP3).

glutamines. There were four unique amino acid mutations (L/M/F113P, K/S/V341R, V357A, and A371V) in VP1 of CAV variant, which were not previously reported (Figure 1). The VP1 residue 394 is a major genetic determinant of virulence, with glutamine $(\mathrm{Q})$ and histidine $(\mathrm{H})$ representing high and low pathogenicity, respectively $[19,20]$. In the CAV variant, residue 394 was glutamine (Q) and was, therefore, highly pathogenic. There were two mutations (E20G, T/S116A) in VP2 and one mutation (D79N) in VP3 of CAV variant, which had not been previously observed (Figure 1). Phylogenetic analysis of the complete genome of CAV variant showed that CAV variant clustered to a clade with the CAV strains in chickens (Figure 4(a)).

3.3. Recombination Analysis. The above results suggested that CAV variant (accession no: KC414026) was a potential recombinant isolate between two CAV strains, namely, CAV strain AF311900 as the minor parent and CAV strain JQ690762 as the major parent (Figure 2) with the recombination breakpoints mapping to position 2,100 (beginning breakpoint) and 158 (ending breakpoint). The recombination region of CAV variant was located in the partial VP1 coding region, the entire $3^{\prime}$ untranslated region (UTR), and a portion of the $5^{\prime}$ UTR (Figure 3). In order to identify if the two breakpoints are precise, we divided the CAV variant genome into two segments: the recombinant region from genomic nucleotide position 2,100-158 and the nonrecombinant region from genomic nucleotide positions 159-2,099. The phylogenetic tree revealed that the breakpoints delimit sequence regions with distinct phylogenies (Figures $4(\mathrm{~b})$ and $4(\mathrm{c})$ ). There was a recombination event in the nucleotide position from 2,100 to 158 of the CAV variant genome, which suggests that recombination could speed up the evolution of CAV.

\section{Discussion}

A CAV variant was isolated from stray cat fecal samples in China, and its genome was sequenced. The variant virus was found in $10 \%$ of samples. The CAV variant was highly pathogenic and had a very high sequence similarity with CAV. Davidson et al. reported that feathers contribute to the horizontal transmission of CAV, by carrying CAV either on their surface or within their feather pulp [21]. Although horizontal transmission is considered the most significant mode of CAV dissemination, the process is not well understood. Further analysis showed that CAV variant was a recombinant virus strain descended from CAV strain JQ690762 and CAV strain AF311900. Homologous recombination is considered rare in single-stranded circular DNA viruses and has not been reported for CAV in cats. Homologous recombination 


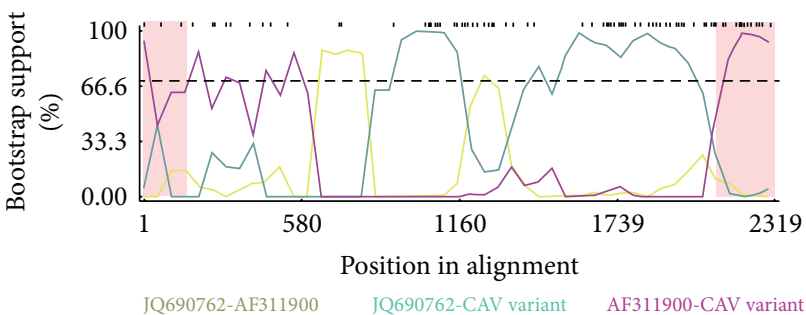

(a)
JQ690762

CAV variant

AF311900

AF311900

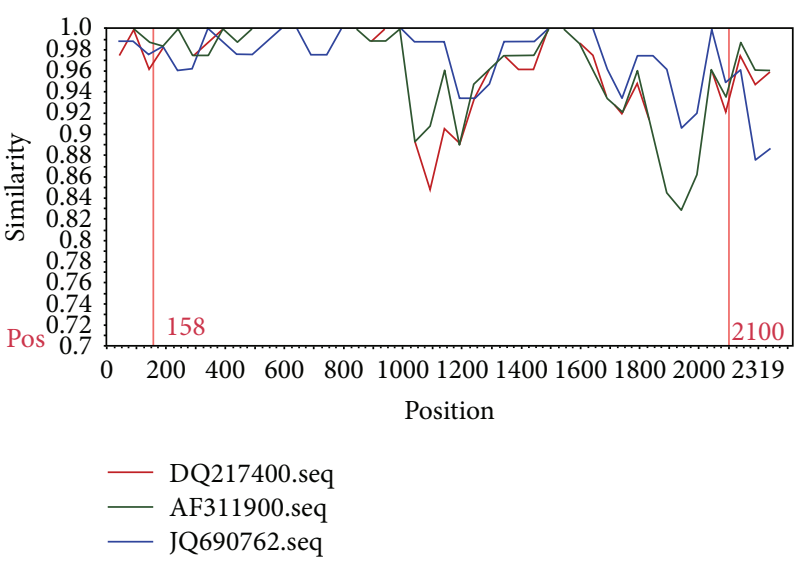

(b)

(c)

FIgURE 2: (a) and (b) Bootscan analysis of the recombinant, major parent, and the minor parent sequences. The analysis was based on a pairwise distance model with a window size of 200, step size of 50, and 1000 bootstrap replicates generated by the RDP4 program. (c) A comparison of the three CAV isolates: AF311900/chicken, JQ690762/human, and CAV variant/cat. The KC414026/CAV variant/cat was used as the query sequence. The DQ217400 was included as an outgroup. The $y$-axis gives the percentage of identity within a sliding window $80 \mathrm{bp}$ wide centered on the position plotted, with a step size between plots of $50 \mathrm{bp}$.

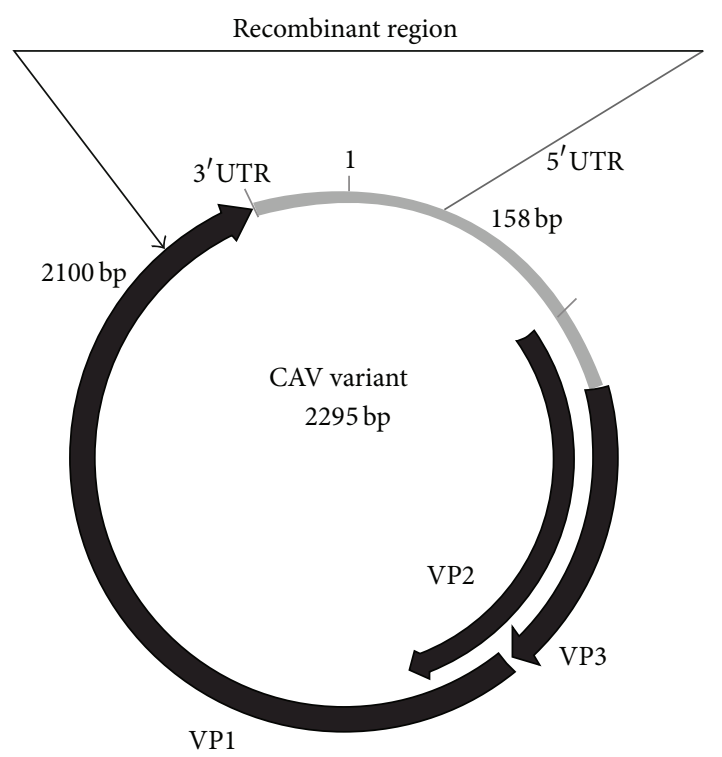

Figure 3: Map of CAV variant (accession no: KC414026) and the recombination breakpoints (beginning breakpoint at 2,100 and ending breakpoint at 158) in alignment with the CAV variant DNA nucleotide sequence. might result in the potential change in viral epidemiology. The results of this study indicate that CAV variant might have originated from CAV-infected chickens. It seems plausible that the stray cats were in contact with and/or ingested CAVinfected/vaccinated chickens. Similarly, humans could be similarly infected by contact with infected cats at the animal shelters. However, the pathogenesis of CAV variant in cats or chickens remains to be elucidated. So far, CAV has been identified in three different species including cats, chickens, and humans. This virus, first reported by Yuasa et al. (1978) [22] from contaminated vaccines in Japan, has a worldwide distribution. Phan et al. confirmed a high prevalence of CAV DNA in diarrhoea and normal faeces from Chilean children [9]. Chu et al. reported that the high rate of codetection of the three gyroviruses (CAV, AGV2/HGV and GyV3) in human specimens may indicate common dietary exposure to foods that contain all three viruses (e.g., chicken skin and meat) or it may imply some undefined dependency or codependency for successful proliferation [10]. As an immune suppression agent, CAV is often associated with secondary bacterial and viral infections. Whether human infection results in reduced immunity to other foreign agents and morbidity requires further study. It is important to understand the extent of sequence variability in CAV, in order to improve the 


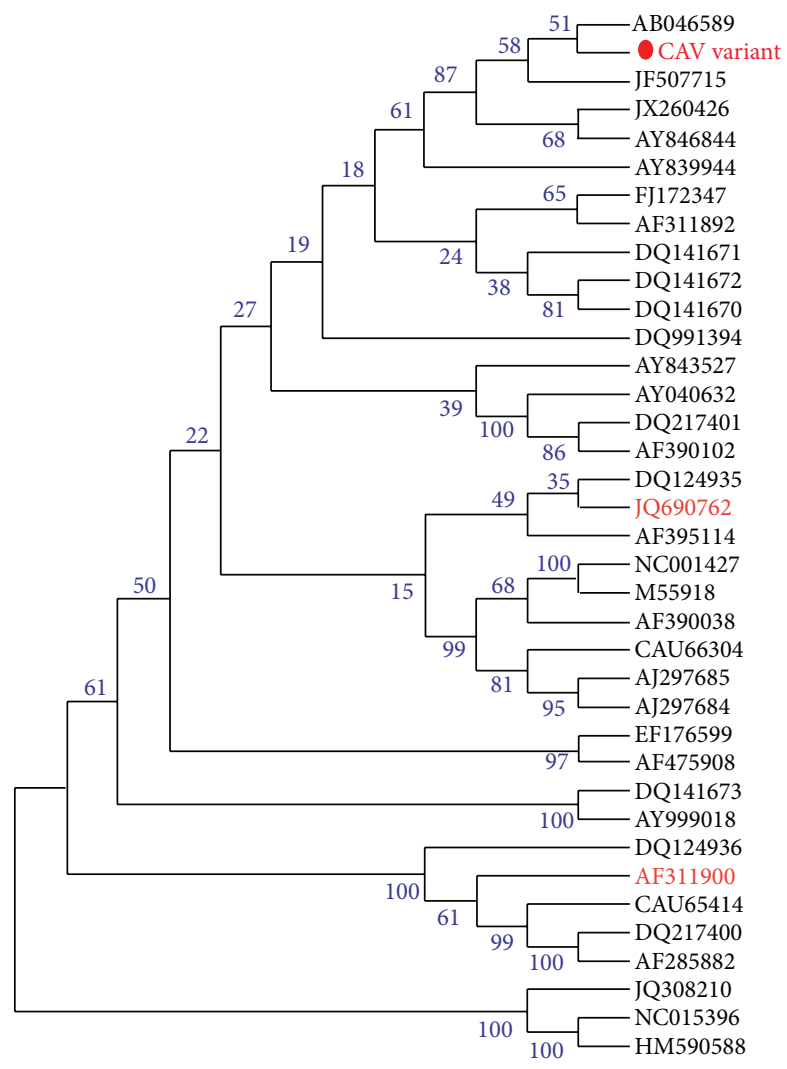

(a)

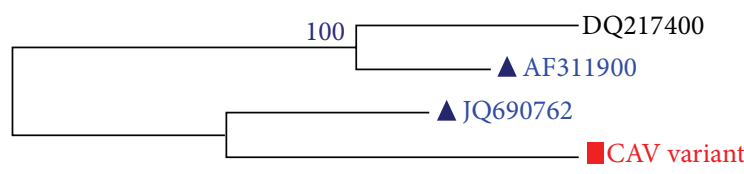

$\vdash 0.005$

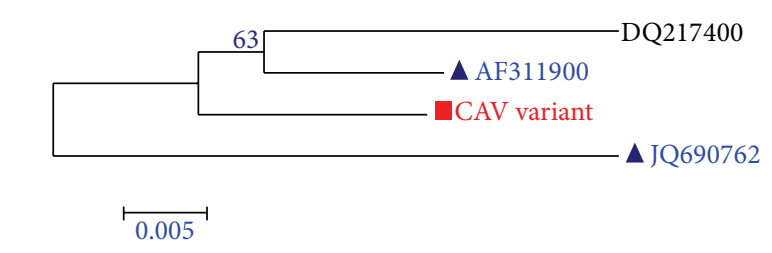

(c)

(b)

FIgure 4: (a) Phylogenetic analysis of 37 CAV isolates in different species based on the genomic sequence. The three analyzed sequences (AF311900, JQ690762, and CAV variant) are indicated in red. The putative mosaic was indicated with "red dot." (b) and (c), respectively, represent the nonrecombinant region (159-2,009) and the recombinant region (2,100-158). The putative recombination is shown with a "red square" and the putative parental lineages are shown with a "blue triangle." The DQ217400 strain was used as an outgroup. The whole sequences were analyzed by using MEGA5.1 software with neighbor-joining (NJ) phylogenetic tree methods together with the novel sequence. Each tree was produced using a consensus of 1000 bootstrap replicates.

management strategies to prevent CAV infections in chickens and to prevent the transmission from chickens to humans or cats. The epidemiology and pathogenesis of this virus in chickens and in cats require further investigation. Our reports also underscore the need to study and monitor circulating CAVs in China.

\section{Conflict of Interests}

All authors declare that they have no conflict of interests related to the research presented in this paper.

\section{Acknowledgments}

The authors thank Prof. Li of the Veterinary College of South China Agricultural University for helping in collecting the fecal samples from stray cats in Guangdong province. This work was supported by grants from Guangdong Momentously Scientific and Technological Project (no. 2009B020201008) and the Strategic Cooperation Project of Guangdong Province \& Chinese Academy (no. 2010B09 0301019). 


\section{References}

[1] T. Taniguchi, N. Yuasa, M. Maeda, and T. Horiuchi, "Hematopathological changes in dead and moribund chicks induced by chicken anemia agent," National Institute of Animal Health quarterly, vol. 22, no. 2, pp. 61-69, 1982.

[2] K. A. Schat, "Chicken anemia virus," Current Topics in Microbiology and Immunology, vol. 331, pp. 151-183, 2009.

[3] M. H. M. Noteborn, G. F. de Boer, D. J. van Roozelaar et al., "Characterization of cloned chicken anemia virus DNA that contains all elements for the infectious replication cycle," Journal of Virology, vol. 65, no. 6, pp. 3131-3139, 1991.

[4] I. Davidson and R. F. Silva, "Creation of diversity in the animal virus world by inter-species and intra-species recombinations: Lessons learned from poultry viruses," Virus Genes, vol. 36, no. 1, pp. 1-9, 2008.

[5] X. H. Zhang, Q. M. Xie, J. Ji et al., "Complete genome sequence analysis of a recent chicken anaemia virus isolate and comparison with a chicken anemia virus isolatefrom human fecal samples in China," Journal of Virology, vol. 86, no. 19, pp. 10896-10897, 2012.

[6] H.-R. Kim, Y.-K. Kwon, Y.-C. Bae, J.-K. Oem, and O.-S. Lee, "Molecular characterization of chicken infectious anemia viruses detected from breeder and broiler chickens in south korea," Poultry Science, vol. 89, no. 11, pp. 2426-2431, 2010.

[7] http://www.ncbi.nlm.nih.gov/nuccore/JQ690762.

[8] V. Sauvage, J. Cheval, V. Foulongne et al., "Identification of the first human Gyrovirus, a virus related to chicken anemia virus," Journal of Virology, vol. 85, no. 15, pp. 7948-7950, 2011.

[9] T. G. Phan, L. Li, M. G. O’Ryan et al., "A third gyrovirus species in human faeces," The Journal of General Virology, vol. 93, no. 6, pp. 1356-1361, 2012.

[10] D. K. Chu, L. L. Poon, S. S. Chiu et al., "Characterization of a novel gyrovirus in human stool and chicken meat," Journal of Clinical Virology, vol. 55, no. 3, pp. 209-213, 2012.

[11] F. Maggi, L. Macera, D. Focosi et al., "Human gyrovirus DNA in human blood, Italy," Emerging Infectious Diseases, vol. 18, no. 6, pp. 956-959, 2012.

[12] J. Bullenkamp, D. Cole, F. Malik et al., "Human Gyrovirus Apoptin shows a similar subcellular distribution pattern and apoptosis induction as the chicken anaemia virus derived VP3/Apoptin," Cell Death \& Disease, vol. 3, p. e296, 2012.

[13] C.-Q. He, N.-Z. Ding, W. Fan, Y.-H. Wu, J.-P. Li, and Y.-L. Li, "Identification of chicken anemia virus putative intergenotype recombinants," Virology, vol. 366, no. 1, pp. 1-7, 2007.

[14] Y. M. Eltahir, K. Qian, W. Jin, and A. Qin, "Analysis of chicken anemia virus genome: evidence of intersubtype recombination," Virology Journal, vol. 8, article 512, 2011.

[15] K. Tamura, D. Peterson, N. Peterson, G. Stecher, M. Nei, and S. Kumar, "MEGA5: molecular evolutionary genetics analysis using maximum likelihood, evolutionary distance, and maximum parsimony methods," Molecular Biology and Evolution, vol. 28, no. 10, pp. 2731-2739, 2011.

[16] D. P. Martin, "Recombination detection and analysis using RDP3," Methods in Molecular Biology, vol. 537, pp. 185-205, 2009.

[17] K. S. Lole, R. C. Bollinger, R. S. Paranjape et al., "Fulllength human immunodeficiency virus type 1 genomes from subtype C-infected seroconverters in India, with evidence of intersubtype recombination," Journal of Virology, vol. 73, no. 1, pp. 152-160, 1999.
[18] R. W. Renshaw, C. Soiné, T. Weinkle et al., "A hypervariable region in VP1 of chicken infectious anemia virus mediates rate of spread and cell tropism in tissue culture," Journal of Virology, vol. 70, no. 12, pp. 8872-8878, 1996.

[19] S. Yamaguchi, T. Imada, N. Kaji et al., "Identification of a genetic determinant of pathogenicity in chicken anaemia virus," The Journal of General Virology, vol. 82, no. 5, pp. 1233-1238, 2001.

[20] S. Simionatto, C. A. da Veiga Lima-Rosa, E. Binneck, A. P. Ravazzolo, and C. W. Canal, "Characterization and phylogenetic analysis of Brazilian chicken anaemia virus," Virus Genes, vol. 33, no. 1, pp. 5-10, 2006.

[21] I. Davidson, N. Artzi, I. Shkoda, A. Lublin, E. Loeb, and K. A. Schat, "The contribution of feathers in the spread of chicken anemia virus," Virus Research, vol. 132, no. 1-2, pp. 152-159, 2008.

[22] N. Yuasa, T. Taniguchi, and I. Yoshida, "Isolation and some characteristics of an agent inducing anemia in chicks," Avian Diseases, vol. 23, no. 2, pp. 366-385, 1978. 

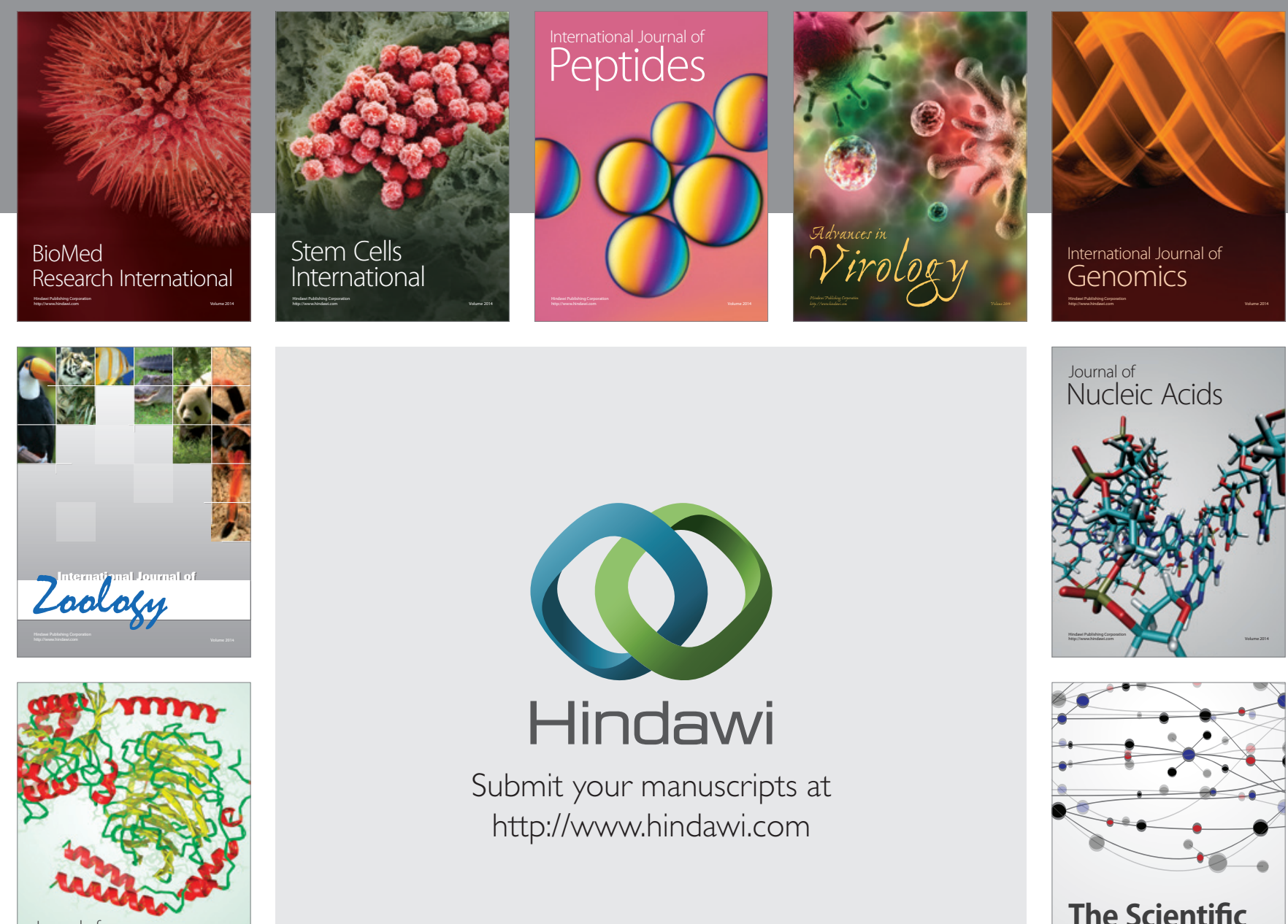

Submit your manuscripts at

http://www.hindawi.com

Journal of
Signal Transduction
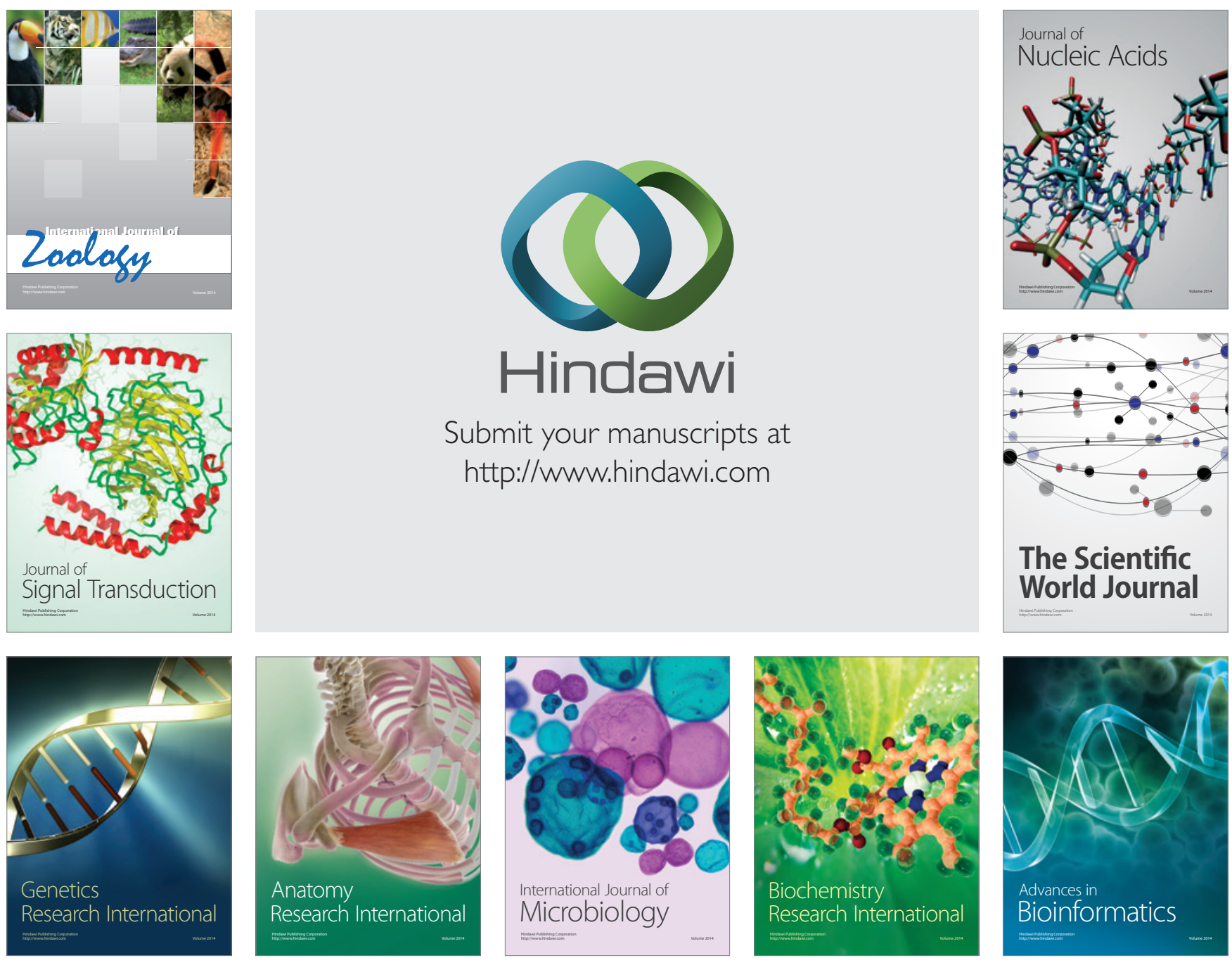

The Scientific World Journal
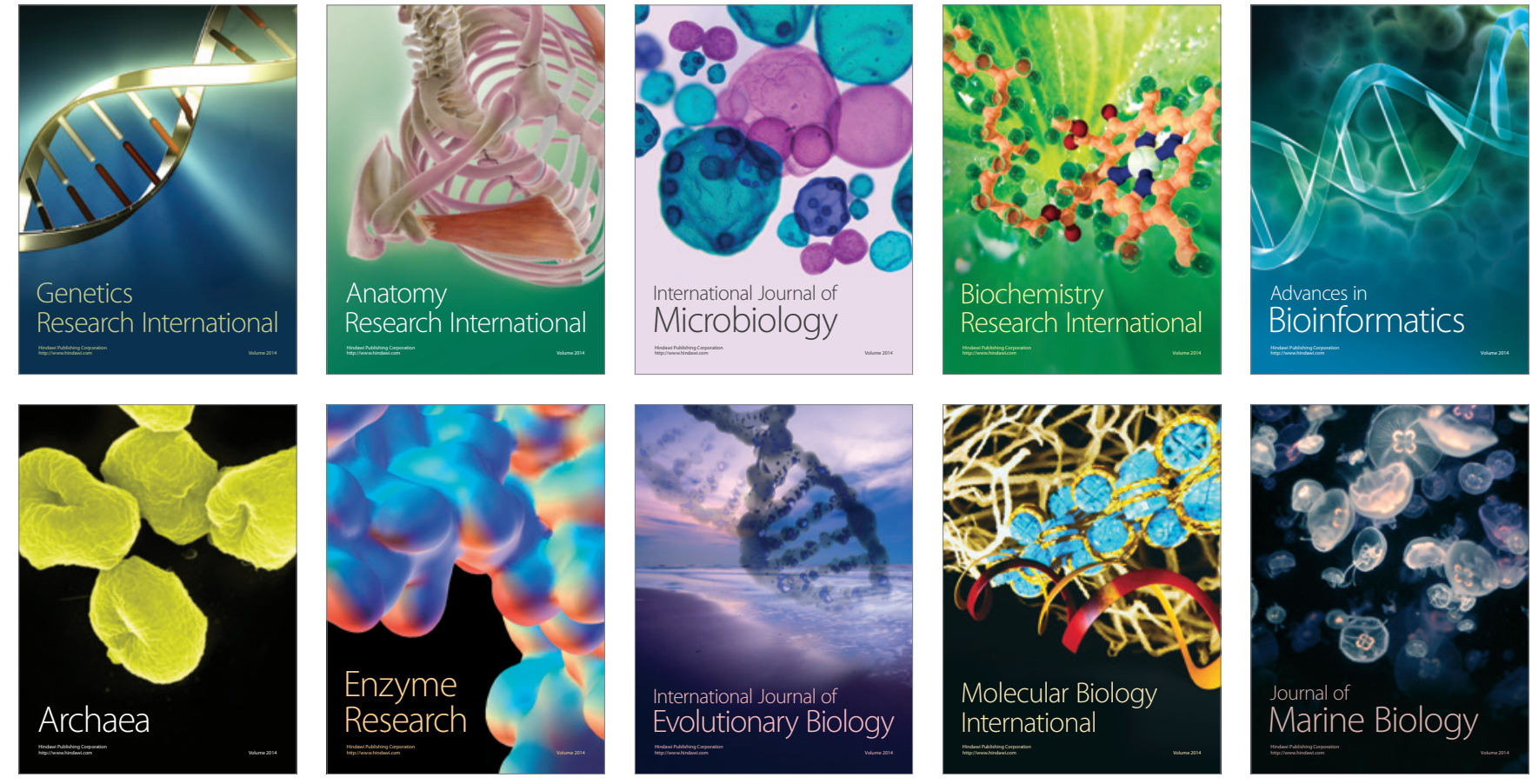